\title{
L1 versus Multiple Vocabulary Teaching Techniques
}

\author{
Sultan Altalhab \\ Curriculum and Instruction Department, College of Education, King Saud University, Riyadh, Saudi Arabia
}

\begin{abstract}
This study compares the effect of using different vocabulary teaching techniques and L1 (Arabic) on vocabulary retention. The participants were 162 Saudi intermediate school students who were divided into two groups. The first group was taught the target words using L1 whilst the second group was taught using multiples teaching techniques (synonyms, body language and pictures). A pre-test, post-test and delayed posttest based on meaning recall were utilised. The findings show that the multiple group achieved superiority over the $\mathrm{L} 1$ group in both post-test and delayed post-test. Also, pictures were found to be the most effective teaching technique while body language was the least.
\end{abstract}

Index Terms - L1, vocabulary, retention, synonyms, body language, pictures

\section{INTRODUCTION}

Using learners' native language or the target language in teaching EFL is one of the areas that has been widely discussed in EFL research. It seems to be a controversial issue in the field of language teaching, as will be shown. Some of the empirical studies that have explored this area will be discussed here, especially those that are concerned with the teaching of vocabulary.

Latsanyphone and Bouangeune (2009) suggested reasons for using L1 in teaching language. For example, some learners, especially those who are shy or lack confidence in their proficiency may hesitate in using L2 in the classroom. L1 use, however, might facilitate helpful activities in class, especially for low proficiency learners. The use of L1 also seems to be popular among low level learners. Many researchers (Swain \& Lapkin, 2000; Nation, 2001; Tang, 2002; Mattioli, 2004) agree that L1 should be used when teaching lower-level learners in the target language. It has also been suggested that learners at a lower level depend on L1 to transfer L2 meaning (Atkinson, 1987; Ellis, 1995; Nation, 1990). Nation (2003) states that "whenever a teacher feels that a meaning-based L2 task might be beyond the capabilities of the learners, a small amount of L1 discussion can help overcome some of the obstacles" (p. 3). In other words, using L1 when necessary is helpful for both the teacher and the student. Moreover, although the communicative approach asserts the use of the target language in teaching, studies have shown that using English alone might be more appropriate for both intermediate and advanced learners (Ramachandran \& Rahim, 2004).

\section{USING L1 AND L2 IN TEACHING VOCABULARY}

One teaching technique for introducing the new vocabulary through the target language is the use of synonyms. Webb (2007) investigated the influence of synonymy on vocabulary learning. Over 80 Japanese learners of English sat 10 tests, both receptive and productive, to examine the impact of synonymy on five aspects of word knowledge. The learners encountered the new words in two conditions: glossed sentences and word pairs. The results revealed that when presented with words whose synonyms they were familiar with the learners outperformed significantly. It can thus be concluded that learning synonyms for known vocabulary is easier than learning vocabulary that does not have any known synonyms. The findings of this study are interesting since little research has been conducted on the effect of synonymy in vocabulary learning, although Webb (2007) did employ nonsense words in the experiment, which has its limitations.

On the other hand, a study by Heltai (1989) looked at the use of translation when teaching vocabulary. He argued that when oral translation is used to teach vocabulary, the activities should be carried out under specific conditions, which is not incompatible with the communicative approach (Heltai, 1989). The first suggested condition is that such translations are not used extensively or when there is no need for them. Secondly, translation exercises should be well prepared. Thirdly, they should be combined with other activities and exercises should be interesting and motivating.

Ramachandran and Rahim (2004) argued that using translation in teaching vocabulary has a positive influence on the meaning of recall and retention. They divided 60 Malaysian ESL elementary learners of English into two groups: an experimental group that received the translation method as the treatment and a control group that received the nontranslation method. The treatment lasted four weeks, and the learners were given a post-test to measure the effectiveness of the treatment. The participants were taught 20 new words. Based on a multiple-choice test with 60 questions, these 20 words received the highest percentage of inaccurate responses. However, receiving the highest percentage of inaccurate responses may suggest that even a very small number of participants answered the questions on these 20 
words correctly. This could indicate that a few participants might have already known the meaning of these words before starting the treatment. Therefore, a more sensitive test is clearly required to ensure that the words used in such a treatment are new for all of the participants. Also, the timing of the treatment chosen in this study appeared to be relatively short for assessing the effectiveness of the method, since some of the words were taught only a week prior to the test.

The findings of Ramachandran and Rahim (2004) were later supported by Latsanyphone and Bouangeune (2009), who carried out a similar study with a larger sample (169 students with a low level of proficiency), although the authors did not clearly state the period of the treatment in their study. Also, as suggested earlier, a more sensitive test should be applied to ensure that the words used in the treatment are new for all the participants, as the pre-test and post-test used were different and the words in the post-test were already known by students. Although the research displays that L1 plays a small but crucial role in communicating meaning, the use of L2 should be increased in the classroom, indeed, its use should be encouraged and it should be employed in classroom management (Nation, 2003, p. 1). Nation (2003) suggested that the use of L2 should be maximised, especially when learners do not have enough opportunities to practise L2 outside the class. One of the ways to achieve this is by managing the classroom in L2. For example, telling the class what to do ('take out your books', 'turn to page 7' etc.), controlling behaviour ('be quiet'), explaining activities ('get into pairs'). These suggestions appear to be useful even with low proficiency learners. If these instructions are repeated in every class, learners will become familiar with the words being used. Another study by Pakzadian (2012) compared L1 and L2 in teaching vocabulary to intermediate level learners. Sixty Persian leaners were involved in comprehension and vocabulary tasks. The results revealed no difference between using L1 or L2 in learners' performance in the comprehension task. Nevertheless, the L1 group showed some superiority in the vocabulary test over the other group.

In the Saudi context, one of the few studies focusing on using Arabic in English classes in Saudi schools was AlNofaie's (2010) study exploring the attitudes of Saudi teachers and students towards using L1 in the classroom. Questionnaires, interviews and four observations from one classroom were used in the data collection. The results revealed that although more than half the students believed using Arabic in class could impede their English learning, $70 \%$ of them reported that they preferred their teachers to use Arabic as a teaching technique. They thought that using Arabic provided them with confidence and helped them to understand better. The teachers justified using Arabic to explain difficult items, especially for students with a low proficiency in English. They employed Arabic in clarifying grammar rules and new words, especially abstract words, whilst concrete words were taught by using pictures and drawings. Nevertheless, their employment of Arabic in the classroom was limited, as they said they wanted to allow more time for students to practise their English. This finding challenges several studies finding that teachers of English at Saudi schools overused Arabic in their classes. The potential reason for this contradiction may be the different context of Al-Nofaie's (2010) study, which was conducted in a female only school, whereas the studies exploring this area in Saudi Arabia were carried out in male only schools.

Alshammari (2011) examined this issue in a different context by asking 95 students and 13 teachers from two Saudi technical colleges to complete questionnaires. The results showed that most students and teachers thought that Arabic should be used in the classroom. More than half of the students reported that employing Arabic was necessary in clarifying new words. A similar number of teachers mentioned that they used Arabic in order to save time, as the students seemed to understand things better that way. Despite the fact that this study was conducted in a different context, Saudi colleges, the issue was not explored in depth because the author only employed questionnaires in his investigation. However, using other research tools, such as interviews and observations, could help investigate the issue further.

The impact of learner proficiency and task type on the amount of Arabic used by Saudi college students in pair work was investigated by Storch and Aldosari (2010). Fifteen pairs from three different proficiency levels completed three tasks (jigsaw, composition and text editing), while their speaking was audio-recorded. The researchers found that there was little use of Arabic during the pair work and that using Arabic was influenced more by the task type rather than the learners' proficiency level. Arabic was used in order to manage a task and to discuss new vocabulary. One of the reasons for the modest use of Arabic in the classroom, as the researchers suggested, might be that the students thought they should not use L1 in L2 classes, which was also reported in a previous study by Storch and Wigglesworth (2003). There were no differences between the learners who used Arabic while working on tasks. However, the lower level learners employed Arabic more than other learners when they worked on editing tasks; this might be due to the increased level of difficulty involved and because it was conducted after doing two previous tasks. This shows that the lower level learners are more likely to resort to L1 than other learners, which might be due to the limited vocabulary that they have which impedes them from using L2. The issue examined in this study was not considered extensively in the literature; however, the method used to determine the participants' level of competence is questionable. The researchers relied on the participants' marks in English at secondary school, their marks in two grammar quizzes and their teacher's evaluation of students' performance throughout the semester. These criteria seem to be insensitive, because the learners' competence might have changed from secondary school to college and the grammar quizzes tested only one aspect of language. Also, these instruments may fail to assess learners' competence in the spoken language. 
Another study by Carson and Kashihara (2012) revealed that Japanese low level EFL learners preferred to deploy L1 whereas the advanced learners showed the reverse.

Debreli and Oyman's (2015) findings were in accordance with Storch and Aldosari's (2010) and Carson and Kashihara's (2012) results in relation to the use of L1 in a L2 class by low level learners. They conducted a study to explore this issue by asking 303 Turkish EFL university students to complete a questionnaire. They found all students with different levels showed positive attitudes towards the use of L1 in a L2 classroom; however, low level learners expressed higher positive attitudes. Nearly half the participants reported that the use of L1 was helpful in understanding the meaning of the new vocabulary. This study recruited only a questionnaire to investigate this issue, however, employing other research tools such as interviews would be helpful to provide more in-depth data. It can be noticed that although different EFL learners, that is in terms of their native language (e.g. Saudi, Japanese, Turkish) were involved in these studies, similar perceptions towards employing L1 were found.

As shown, existing research revealed that using L1 in teaching vocabulary could affect learning vocabulary positively, especially in terms of recall and retention. Also, using L1 may be more suitable for beginners, rather than intermediate and advanced learners. In the existing research, learners showed positive attitudes towards using L1 in teaching L2.

\section{Body LANGUAGE AND PiCTUREs (AS NONVERB AL TECHNIQUES) IN THE EFL Classroom}

Body language has been defined as "real, complex, extremely precise, and inextricably bound to our use of spoken languages as a way of accentuating, highlighting, and amplifying what we mean" (Thomas \& Tchudi, 1999, p. 133). This suggests that body language seems to be an unconscious process which speakers resort to as a means of delivering certain thoughts. It should be noted that body language in the current study refers to the following: movement, embodiment and gestures.

Non-verbal behaviours considered in the large body of research focus mainly on the use of gestures in the classroom (e.g. Sime, 2006; Rosborough, 2014). Gestures play a role in communicative and cognitive abilities in language learning and can be used as a means by which to deal with any difficulties in learning (Gullberg, 2006). Gullberg, de Bot and Volterra (2008) summarised the role of gestures in language development, focusing on the following aspects: "gestures as a medium of language development, gestures as a reflection of language development and gestures as language development itself” (p. 150).

A number of studies have examined the use of body language in the EFL classroom. One of these studies by Rosborough (2014) explored the role of body movement and gestures in an English language class in terms of delivering meaning. He found that body movement and gestures play a key role in meaning-making. Sime (2008) investigated learners' perceptions of using gestures generated by their teachers. Videotaping was used to record teachers' verbal and non-verbal behaviours, while interviews with some learners were also employed. The results revealed that gestures were employed to deliver meaning and as a means of interaction in the classroom. Smotrova and Lantolf, (2013) investigated the use of a gesture-speech interface while teaching the meaning of new vocabulary in the EFL classroom. They found gestures helpful for learners, aiding them in understanding the meaning of vocabulary. They suggested that only using verbal teaching techniques might not be enough to deliver meaning, however. In addition to facilitating meaning, Macedonia and Knösche (2011) examined the role of gestures in retaining the meaning of concrete words. The results showed that gestures positively affect the consolidation of vocabulary meaning.

Lanzaraton (2004) explored an ESL teacher employing both gestures and speech in teaching vocabulary. Three classes with this teacher were videotaped and the discourse in these classes analysed. Although the number of participants in this study was limited, the study provided an insight into the role of non-verbal behaviours in the classroom. The findings suggested that non-verbal behaviours are a fundamental aspect in L2 learning, providing learners with comprehensible input. Recently, Chan (2018) asserted the role of body language in learning the pronunciation of a new vocabulary by reviewing a number of studies in this area. She suggested that body language can be an effective way to ensure accurate pronunciation.

In vocabulary studies concerned with vocabulary teaching techniques, the use of gestures was found to be one of the techniques employed by EFL teachers to introduce new words. For example, Waring, Creider and Box (2013) investigated the vocabulary teaching techniques used by two teachers through a conversation analytic framework. They found gestures one of the techniques deployed by one of the teachers in explaining vocabulary.

Another nonverbal technique to be used in teaching vocabulary is pictures. There is a dearth of research on the role of employing pictures in vocabulary learning, especially in an EFL context. One of the few studies that examine this aspect was conducted by Chen (1990), who compared two methods of teaching: using L1 and using pictures to teach French words to Cantonese students. The participants in the test were required to use L2 for items congruent (i.e. L1 for L1 translation) and incongruent (i.e. pictures for L1 translation). The results showed that the participants who learned L2 with L1 were faster in translating the meanings, whereas the participants in the picture group performed better at naming pictures. Nevertheless, the main effect of the learning method was not revealed. Similar techniques were examined by Lotto and De Groot (1998), where two groups of Dutch students were introduced to Italian words. The results were similar to Chen's (1990) results that indicated the effect of congruency when the test items were similar to 
the method of learning. However, the main effect of the learning method was found in Lotto and De Groot's (1998) study.

In the EFL context, a recent study by Emirmustafaogua and Gökmena (2015) compared the impact of using pictures and L1 on vocabulary retention for 75 young Turkish learners. The findings showed that both pictures groups and the L1 group achieved equal levels of performance. After discussing some of the studies conducted on the effectiveness of employing pictures in teaching new vocabulary, it can be noticed the findings in these studies are still contradicted. Also, the focus of these studies was on comparing the pictures to the use of L1 rather than other teaching techniques. Therefore, the current study aims to investigate the following research questions:

1. Is L1 as a vocabulary teaching technique more effective than multiple teaching techniques (synonym, body language, pictures)?

2. Which one of these vocabulary teaching techniques, synonyms, body language and pictures, lead to better vocabulary retention?

\section{Methodology}

\section{A. Participants}

The sample in this study consisted of 162 male Saudi students in three intermediate schools in Riyadh, Saudi Arabia. The total number of participants was initially 170; however, some of them were excluded from the study due to their absence in one of the post-tests. The participants were 13-14 years old and native speakers of Arabic. They had studied English as a subject for four years, three years at primary school with two classes a week and one year at intermediate school where each class was 45 minutes long at both the primary and intermediate school level.

\section{B. Procedure}

First, a pre-test was used to examine the participants' knowledge of the target vocabulary. Fifteen words chosen from the low frequency words were employed in the study. The frequency levels of the target words were determined using Vocabulary Profiler, which is available on the Compleat Lexical Tutor website. The type of words was considered in terms of possibility, if it could be explained by pictures, body language and synonyms. The pre-test asked the students to provide the meaning of the target words. The students were divided into two groups. The first group was the L1 group where the target words were explained used only L1, while the second group was taught through synonyms, body language and pictures. In the latter group, the target words were equally divided into three groups as each group included five words and were taught using a certain technique. A post-test was conducted on the following day. One month later, the delayed post-test was utilised. The maximum score in the tests was fifteen as each answer was given one point.

\section{Data Analysis}

In order to examine the impact of the vocabulary teaching techniques employed in the study, the data were analysed using SPSS. Means of the post-test and delayed post-test were measured. A T-test was also employed to find any significant differences between the participants' performance in the two study groups.

\section{RESULTS AND DISCUSSION}

As noted in the previous section, this study was conducted in order to determine the effectiveness of L1 explanations versus the use of synonyms, body language and pictures in L2 learning. Additionally, this study also compared the effectiveness of synonyms, body language and pictures as individual techniques. The results of the word meaning recall tests are presented in the current section, with each of the two research questions addressed based on the results of the data analysis.

Q1: Is L2 language learning greater when using L1 explanations or when using alternative techniques (synonyms, body language and pictures)?

In order to address the above research question, the test data were analysed in terms of the mean scores for the correct test responses. Table 1, below, presents the results of the data analysis for the two groups (L1 explanations and synonyms, body language and pictures), using post-test (1 day after the pre-test) and delayed post-test (1 month after the post-test) scores, with mean values provided. Each of the tests contained items relevant to the specific teaching approach used for each of the groups. As illustrated in the table, it can be seen that the mean scores for the group instructed using synonyms, body language and pictures were higher across both tests (12.45 for the post-test and 6.18 for the delayed post-test). They were higher than the mean scores for the group instructed using only L1 vocabulary ( 8.23 for the post-test and 1.95 for the delayed post-test). 


\begin{tabular}{|c|c|c|c|c|c|c|c|c|}
\hline \multicolumn{9}{|c|}{ TABLE I. } \\
\hline Groups & & $\mathrm{N}$ & Mean & $\begin{array}{c}\text { Std. } \\
\text { Deviation }\end{array}$ & $\begin{array}{l}\text { Std. Error } \\
\text { Mean }\end{array}$ & T-test & Df & Sig. \\
\hline \multirow{2}{*}{$\underset{\substack{\vec{w} \\
\oplus}}{\widehat{\Xi}}$} & L1 group & 82 & 8.23 & 3.305 & 0.365 & \multirow{2}{*}{-8.293} & \multirow{2}{*}{160} & \multirow{2}{*}{0.000} \\
\hline & $\begin{array}{l}\text { Multiple teaching techniques } \\
\text { group }\end{array}$ & 80 & 12.45 & 3.166 & 0.354 & & & \\
\hline \multirow{2}{*}{$\underset{\overrightarrow{0}}{\stackrel{d}{0}}$} & L1 group & 82 & 1.95 & 1.898 & 0.210 & \multirow{2}{*}{-7.454} & \multirow{2}{*}{103.495} & \multirow{2}{*}{0.000} \\
\hline & $\begin{array}{l}\text { Multiple teaching techniques } \\
\text { group }\end{array}$ & 80 & 6.18 & 4.709 & 0.526 & & & \\
\hline
\end{tabular}

In order to compare the scores of the L1 vocabulary group with the group instructed using synonyms, body language and pictures, an independent t-test was performed on the data for each of the tests (post-test and delayed post-test). The results of the independent t-test indicate that language meaning recall was stronger amongst the group taught using synonyms, body language and pictures than amongst the group taught using only L1 vocabulary. The differences between the two groups were found to be statistically significant in both the post-test $(t=-8.293, p=0.000)$ and the delayed post-test $(\mathrm{t}=-7.454, \mathrm{p}=0.000)$ (see Table 1$)$.

The results of the data analysis indicate that the retention of new L2 vocabulary is significantly impacted by the teaching method involved, with the use of synonyms, body language and pictures appearing to be more effective than the use of explanations in the learner's native language alone. Given this, the results of the post-test and delayed posttest indicate that the use of L1 explanations in combination with no other technique is insufficient when teaching new words to L2 learners. This is an interesting finding, given that researchers such as Latsanyphone and Bouangeune (2009), Pakzadian (2012) and Ramachandran and Rahim (2004) all found that L1 explanations had a positive impact on language learning with regards to vocabulary acquisition. However, all these studies examined L2 language learning from a different perspective compared to the present study, comparing the use of L1 and L2 languages. This could account for the disparity between the current findings and the findings presented in these earlier works. Another point worth noting is that some Saudi researchers, such as Al-Nofaie (2010) and Alshammari (2011), found that L1 explanations were viewed favourably by both English language learners and instructors when explaining the meaning of unfamiliar L2 words. This indicates that despite the results obtained in the current study, L1 explanations are still perceived positively in real-world language learning practice. The reason for this could be that learners feel more comfortable using L1 vocabulary when dealing with new L2 words, therefore increasing their preference for L1 language support when learning to speak English.

As noted earlier in this article, a pre-test was conducted the day prior to the post-test. The purpose of the pre-test was to assess learners' baseline L2 proficiency. Based on the results of the pre-test, which showed that none of the learners knew the meaning of the selected L2 words, the participants involved in the current study can be considered low-level L2 learners. Whilst researchers such as Carson and Kashihara (2012), Debreli and Oyman (2015), Latsanyphone and Bouangeune (2009) and Storch and Aldosari (2010) suggest that L1 vocabulary could be useful when teaching such students, it appears that this has no significantly positive impact on learning new L2 words. Rather, the use of additional techniques - such as synonyms, body language and pictures - is recommended in order to help learners retain the meaning of unknown L2 words.

Q2: Is L2 word meaning retained more effectively using synonyms, body language or pictures?

Whilst the first research question presented in this paper sought to explore the effectiveness of L1 vocabulary in comparison to the use of the selected alternative techniques (synonyms, body language and pictures), the second research question focused on examining the effectiveness of each of the alternative techniques individually. Therefore, each of the individual techniques was analysed for each of the two tests (post-test and delayed post-test). The results pertaining to the second research question are now discussed. Table 2, below, illustrates the mean scores of all correct responses during each of the tests, with "body language 1" referring to the body language technique in the post-test, "body language 2 " referring to the body language technique in the delayed post-test, and so on. 


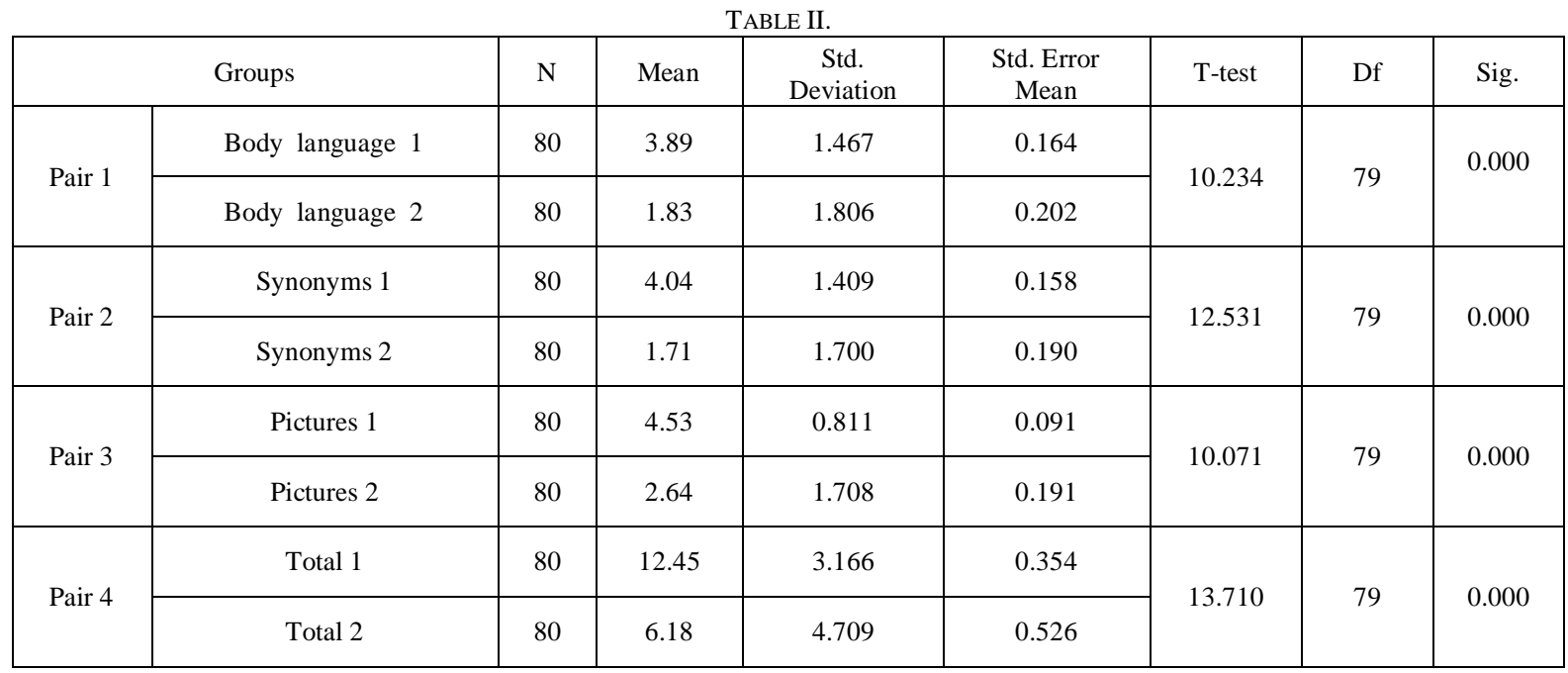

The post-test analysis illustrates a mean score of 3.89 for the use of body language, 4.04 for the use of synonyms, and 4.53 for the use of pictures. With the mean score being greatest for the use of pictures when recalling the meaning of new L2 words, the results of the analysis indicate that out of all of the three chosen techniques (synonyms, body language, and pictures), the most effective technique instructors can use when teaching the meaning of new L 2 words is pictures. The second most effective technique is therefore suggested as synonyms, with the third most effective technique being body language. The results of the delayed post-test, conducted one month after the post-test, suggest similar implications, with the use of pictures having the highest mean score out of the three techniques, at 2.64. The use of body language and synonyms were found to be slightly less effective based on the results of the delayed post-test, with mean scores of 1.83 and 1.71 , respectively.

These findings are in line with the results of other researchers, such as Chen (1990) and Lotto and De Groot (1998), who compared the use of pictures in language teaching to the use of one other language teaching approach. Both studies indicated that the acquisition of new words is significantly improved by using pictures to provide meaning. Conversely, the findings presented in the current paper conflict with the findings of a recent existing study (i.e., Emirmustafaogua \& Gökmena, 2015) in which it was indicated that the use of L1 explanations, compared to the use of pictures for language teaching, had no significant impact in terms of measured L2 learning outcomes.

With regards to the effectiveness of synonyms in teaching L2 learners the meaning of new words, the findings of the present study are in accordance with that of earlier studies, such as those conducted by Latsanyphone and Bouangeune (2009), Pakzadian (2012) and Ramachandran and Rahim (2004). Whilst these studies aimed to explore the use of L1 versus L2 vocabulary, the similarity between the findings of these studies and the current study regarding the impact of synonym use remains noteworthy. Both the current study and these earlier studies indicate that the use of synonyms as a L2 teaching tool is less effective than other techniques (such as the use of pictures) when teaching new words to L2 students. These findings therefore present valuable implications for language teachers and may be considered when constructing teaching plans.

Body language was found to be the least effective of the three chosen L2 teaching methods based on post-test scores, with the mean score for body language being similar to that of synonyms based on the analysis of delayed post-test scores. Interestingly, previous researchers, such as Lanzaraton (2004), Rosborough (2014) and Sime (2006), presented opposing findings in their research. It is possible that the disparity between the findings of these researchers and the findings presented in the current study could be due to the non-experimental nature of the previous studies. Additionally, the research instruments used in the previous studies were markedly different to the instruments adopted in the current study, and none of the previous studies compared the impact of body language to the impact of other teaching methods with regards to word meaning recall.

\section{CONCLUSION}

This study seems to have been the first to examine the effectiveness of L1 as a vocabulary teaching technique versus various vocabulary teaching techniques (synonyms, body language and pictures) in consolidating the meaning of new words. The results revealed that the use of multiple vocabulary teaching techniques (synonyms, body language and pictures) led to better retention. When a comparison was conducted between these techniques, employing pictures achieved the highest scores in the tests while body language scored the least. The results emphasise the importance of recruiting different vocabulary teaching techniques rather than the direct use of L1. Although this study has provided an insight into the use of different vocabulary teaching techniques, it has examined only one aspect of vocabulary knowledge, meaning. Therefore, it is suggested that further research can consider other aspects of vocabulary knowledge. 


\section{REFERENCES}

[1] AL-Nofaie, H. (2010). The attitudes of teachers and students towards using Arabic in EFL classrooms in Saudi public schools a case study. Novitas-ROYAL (Research on Youth and Language), 4(1), 64-95.

[2] Alshammari, M. M. (2011). The use of the mother tongue in Saudi EFL classrooms. Journal of International Education Research, 7(4), 95-102. DOI: https://doi.org/10.19030/jier.v7i4.6055.

[3] Atkinson, D. (1987). The mother tongue in the classroom: a neglected resource? English. Language Teaching Journal, 41(4), 241- 247. DOI: https://doi.org/10.1093/elt/41.4.241.

[4] Carson, E., \& Kashihara, H. (2012). Using the L1 in the L2 classroom: The students speak. The Language Teacher, 36(4), 4148.

[5] Debreli, E., \& Oyman, N. (2015), Students' preferences on the use of mother tongue in English as a foreign language classrooms: is it the time to re-examine English-only policies? English Language Teaching, 9(1), 148-162. DOI: doi:10.5539/eltv9n1p148.

[6] Emirmustafaolu, A, \& Gökmen. D. U. (2015). The effects of picture vs. translation mediated instruction on L2 vocabulary learning. Procedia - Social and Behavioral Sciences, 199, 357-362. https://doi.org/10.1016/j.sbspro.2015.07.559.

[7] Gullberg, M. (2006). Some reasons for studying gesture and second language acquisition (Hommage à Adam Kendon). International Review of Applied Linguistics, 44(2), 103-124. DOI: 10.1515/IRAL.2006.004.

[8] Gullberg, M., de Bot, K. \& Volterra, V. (2008). Gestures and some key issues in the study of language development. Gesture, 8(2), 149-179. DOI: https://doi.org/10.1075/gest.8.2.03gul.

[9] Heltai, P. (1989). Teaching vocabulary by oral translation. ELT Journal, 43(4), $288-293$. DOI: https://doi.org/10.1093/elt/43.4.288.

[10] Latsanyphone, S. \& Bouangeune, S. (2009). Using L1 in teaching vocabulary to low English proficiency level students: A case study at the National University of Laos. English Language Teaching, 2(3), 186-193.

[11] Lazaraton, A. (2004). Gesture and speech in the vocabulary explanations of one ESL teacher: A microanalytic inquiry. Language Learning, 54(1), 79-117. DOI: https://doi.org/10.1111/j.1467-9922.2004.00249.x.

[12] Lotto, L., \& De Groot, A. M. B. (1998). Effects of learning method and word type on acquiring vocabulary in an unfamiliar language. Language Learning, 48(1), 31-69. DOI: https://doi.org/10.1111/1467-9922.00032.

[13] Macedonia, M. \& Knösche, T. R. (2011). Body in mind: How gestures empower foreign language learning. Mind, Brain, and Education, 5(4), 196-211. DOI: https://doi.org/10.1111/j.1540-4781.2013.12008.x.

[14] Mattioli, G. (2004). On native language intrusions and making do with words: Linguistically homogenous classrooms and native language use. English Language Forum, 42(4), 20-25.

[15] Nation, I. S. P. (2003). The role of the first language in foreign language learning. The Asian EFL Journal, 5(2), 1-8.

[16] Nation, I. S. P. (2001). Learning vocabulary in another language. Cambridge: Cambridge University Press. DOI: https://doi.org/10.1017/CBO9781139524759.

[17] Nation, I. S. P. (1990). Teaching and Learning Vocabulary. New York: Newbury House.

[18] Pakzadian, M. (2012). The effect of L1 on learning new L2 vocabulary among intermediate proficiency level students. Theory \& Practice in Language Studies, 2(6), 1147-1152. DOI: DOI: 10.4304/tpls.2.6.1147-1152.

[19] Ramachandran, S. D., \& Rahim, H. A. (2004). Meaning recall and retention: The impact of the translation method on elementary level learners' vocabulary learning. RELC Journal, 35(2), 161-178. DOI: https://doi.org/10.1177/003368820403500205.

[20] Rosborough, A. (2014). Gesture, meaning-making, and embodiment: Second language learning in an elementary classroom. Journal of Pedagogy, 5(2), 227-250. DOI: https://doi.org/10.2478/jped-2014-0011.

[21] Smotrova, T. \& Lantolf, J. P. (2013). The function of gesture in lexically focused L2 instructional conversations. The Modern Language Journal, 97(2), 397-416. DOI: https://doi.org/10.1111/j.1540-4781.2013.12008.x.

[22] Sime, D. (2008). Because of her gesture, it's very easy to understand learners' perceptions of teachers' gestures in the foreign language class. In S. G. McCafferty \& S. G. Stam (Eds.), Gesture: Second Language Acquisition and Classroom Research. (pp. 259-280). New York: ESL \& Applied Linguistics Professional Series.

[23] Sime, D. (2006). What do learners make of teachers' gestures in the language classroom? IRAL, 44(2), 211-230. DOI: 10.1515/iral.2006.009 DOI: https://doi.org/10.1515/IRAL.2006.009.

[24] Smotrova, T., \& Lantolf, J. P. (2013). The function of gesture in lexically focused L2 instructional conversations. The Modern Language Journal, 97(2), 397-416. DOI: https://doi.org/10.1111/j.1540-4781.2013.12008.x.

[25] Storch N., Aldosari A. (2010). Learners' use of first language (Arabic) in pair work in an EFL class. Language Teaching Research, 14(4), 355-375. DOI: https://doi.org/10.1177/1362168810375362.

[26] Storch, N., \& Wigglesworth, G. (2003). Is there a role for the use of the L1 in an L2 setting? TESOL quarterly, 37(4), 760-770. DOI: $10.2307 / 3588224$.

[27] Swain, M. \& Lapkin, S. (2000). Task-based second language learning: the uses of the first language. Language Teaching Research, 4(3), 251-274. DOI: https://doi.org/10.1177/136216880000400304.

[28] Tang, J. (2002). Using L1 in the English classroom. English Teaching Forum, 40(1), 36-44.

[29] Thomas, L. \& Tchudi, S. (1999). The English Language: An owner's manual. Boston: Allyn and Bacon.

[30] Waring, H. Z., Creider, S. C., \& Box, C. D. (2013). Explaining vocabulary in the second language classroom: A conversation analytic account. Learning, Culture and Social Interaction, 2(4), 249-264. DOI: https://doi.org/10.1016/j.lcsi.2013.08.001.

[31] Webb, S. (2007). The effects of repetition on vocabulary knowledge. Applied Linguistics, 28(1), 46-65. DOI: https://doi.org/10.1093/applin/aml048. 
Sultan Altalhab is an Assistant Professor at College of Education at King Saud University in Saudi Arabia. He is interested in teacher education and vocabulary research. He teaches undergraduate and postgraduate TESOL courses and supervises postgraduate research projects. Email: saltalhab@ksu.edu.sa 